\title{
SEVERE GASTROINTESTINAL MANIFESTATIONS COMPLICATING HENOCH-SCHÖNLEIN PURPURA IN ADULT: A RARE CASE IN INDONESIA
}

\author{
WILLIAM RAY CASSIDY*, KETUT SURYANA, DEWI CATUR WULANDARI \\ Department of Internal Medicine, Wangaya Regional General Hospital, Jalan Kartini No.133, Dauh Puri Kaja, Denpasar Utara, Dauh Puri \\ Kaja, Denpasar Utara, Denpasar, Bali. Email: rsudwangaya.dpskota@gmail.com
}

Received: 04 August 2018, Revised and Accepted: 06 September 2018

\section{ABSTRACT}

Henoch-Schönlein purpura (HSP), also known as immunoglobulin A vasculitis, is a self-limiting, small vessel systemic vasculitis rarely found in adults characterized by palpable purpura, arthritis or arthralgia, gastrointestinal, and renal involvement. We report a case of a 31-year-old male with HSP complicated with severe gastrointestinal manifestations mimicking acute abdomen. He was successfully managed with conservative approach. Meticulous diagnosis, treatment, and long-term monitoring are important to reduce patient morbidity.

Keywords: Adult-onset Henoch-Schönlein Purpura, Severe bowel angina, Small vessel vasculitis.

(C) 2018 The Authors. Published by Innovare Academic Sciences Pvt Ltd. This is an open access article under the CC BY license (http://creativecommons. org/licenses/by/4. 0/) DOI: http://dx.doi.org/10.22159/ajpcr.2018.v11i11.28911

\section{INTRODUCTION}

Henoch-Schönlein purpura (HSP) is one of the most common small vessel vasculitides in children. It is characterized by nonthrombocytopenic, leukocytoclastic vasculitis with immunoglobulin A (IgA) deposition [1]. However, HSP cases in adults are uncommon. It is also related to more severe clinical episodes and may leave longterm target organ complications in a number of patients [1,2]. This prompts a meticulous investigation and management to prevent lasting complications. Abdominal pain is a common finding in HSP with varying severity; it may be easily mistaken for an acute abdomen if the underlying cause is overlooked. We report a case of an adult-onset HSP with severe gastrointestinal symptoms successfully treated with steroid therapy.

\section{CASE REPORT}

A 31-year-old man came to internal medicine clinic with a 2-day history of rash over his legs. The lesions were small at first, increasing in size to red plaques overnight. There were no burning sensations on the skin lesion; he only felt a slight non-disturbing itch. He also experienced diffuse abdominal pain and joint pain all over his body, without any limitations to movement. There were no changes in bowel habit, he was not nauseous, urinary complaints were absent. Significant medical history was a sore throat about 1 week before the skin complaints, in which he took medications from primary health-care center (he was unable to recall the drug names). He denied any previous history of drug allergies.

On examination, he was alert with normal vital signs. There were no abnormalities in the head and neck region. Respiratory and cardiovascular physical examinations were unremarkable. The abdomen was flat on inspection, bowel sound was normal, pain after soft palpation was noticed in all quadrants without muscle guarding, and no enlargement of liver and spleen was found either. Red, palpable purpuras were seen all over his lower extremities (Fig. 1), several smaller lesions were found on his elbow as well. Joint swelling or redness was absent. A working diagnosis of HSP was established and the patient was admitted to the internal medicine ward. The patient was started on $62.5 \mathrm{mg}$ of intravenous methylprednisolone every $12 \mathrm{~h}$. Ceftriaxone was also administered due to suspicion on secondary infection. To ease the joint pain, intravenous paracetamol was chosen. Laboratory tests revealed leukocytosis (white blood cells $15.590 / \mathrm{uL}$ ) with neutrophilia, normal hemoglobin (16.5 g/dL), hematocrit (49.5\%), normal platelet count $(332.000 / \mathrm{uL})$, hypoalbuminemia $(3.0 \mathrm{~g} / \mathrm{dL})$, normal kidney function (urea $19 \mathrm{mg} / \mathrm{dL}$, serum creatinine $(0.9 \mathrm{mg} / \mathrm{dL})$, normal alanine aminotransferase (48 U/L), and aspartate aminotransferase (32 U/L). Urinalysis result was unremarkable. Neither gross nor microscopic hematurias were seen, and proteinuria was absent. Dermatology department was consulted and topical desoximetasone + gentamycin ointment was added to therapy. Skin biopsy could not be done in our hospital due to lack of related equipment.

On the first night of admission, the patient began to feel nauseous. He started vomiting profusely on the following day. There was no blood or blood clots observed in the vomitus. $4 \mathrm{mg}$ of intravenous ondansetron was administered every $8 \mathrm{~h}$, in addition to intravenous esomeprazole $40 \mathrm{mg}$ once daily. On the next day, the abdominal pain worsened with muscle guarding, which did not present before. He was also complaining of difficulty in defecating. Bowel movement was still audible with auscultation and no distention was seen. An urgent surgery consultation was commenced, arising suspicion of acute abdomen. Despite the patient's clinical condition, the surgeon decided not to conduct a surgical intervention. Plain abdominal radiography appeared unremarkable (Fig. 2).

Abdominal distention was observed on the $4^{\text {th }}$ day. On physical examination, shifting dullness was positive. The diffuse abdominal pain did not decrease in intensity. Abdominal ultrasound examination revealed free fluid in the abdominal cavity, pelvic cavity, and McBurney area (Fig. 3). Pleural effusion was also visible, although the patient never complained of shortness of breath and his respiratory rate was always normal. Over the next 3 days, the abdominal pain resolves spontaneously without any intervention, the patient's abdomen was no longer distended, and his bowel habit returned to normal. Furthermore, the purpuric rashes became less visible (Fig. 4) and his joint pain became milder. The patient was discharged uneventfully. Oral methylprednisolone treatment was continued $8 \mathrm{mg}$ twice daily, and he was scheduled for a follow-up visit to internal medicine and dermatology clinics.

\section{DISCUSSION}

HSP is a self-limiting, systemic, non-granulomatous, autoimmune complex, and small vessel vasculitis. It is associated with multiorgan 
involvement [3]. Schönlein first described a syndrome of acute purpura and arthritis in children in 1837. Manifestations of colicky abdominal pain and nephritis were then added by Henoch in 1874 [4].

The exact cause of HSP is still unknown, but it is established that IgA has an important role in the pathophysiologic process [5]. Bacterial and viral infections, drugs, and autoimmune mechanisms may trigger the formation of antigen and antibody complex such as IgA. Streptococcal infection with positive antistreptolysin-0 titer has been reported to hypothetically initiate the immune cascade in HSP. Only IgA1 is found in HSP. Immune complexes, including IgA deposit in small vessel walls, activate the complement pathway, leading to polymorphonuclear cells accumulation causing inflammation and vessel wall necrosis (focal fibrinoid necrosis) without granulomatous reaction, and with associated erythrocyte extravasation, consistent with a form of leukocytoclastic vasculitis. The aforementioned vasculitis is most likely responsible to the development of edema and hemorrhage $[3,6]$. The patient, in this case, has just recovered from upper respiratory tract infection, which might have been the trigger to HSP.

As the most common systemic vasculitis affecting children, HSP has the annual incidence of $3-26 / 100.000$, most frequently found in children from 4 to 7 years old. In adults, the incidence of HSP is relatively rare with the annual incidence ranging from 0.1 to $1.8 / 100.000$ individuals [5]. The self-limiting nature of HSP might also mask the true incidence rate [3]. The overall incidence of adult-onset HSP in Indonesia to this date is still unclear, most probably due to the lack of reports or underdiagnosis.

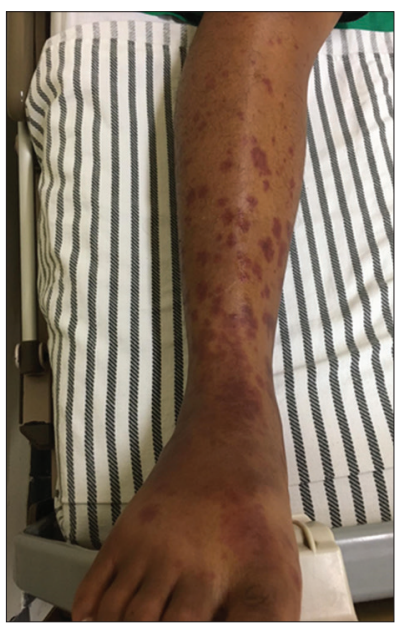

Fig. 1: The right leg showing palpable erythematous purpuras

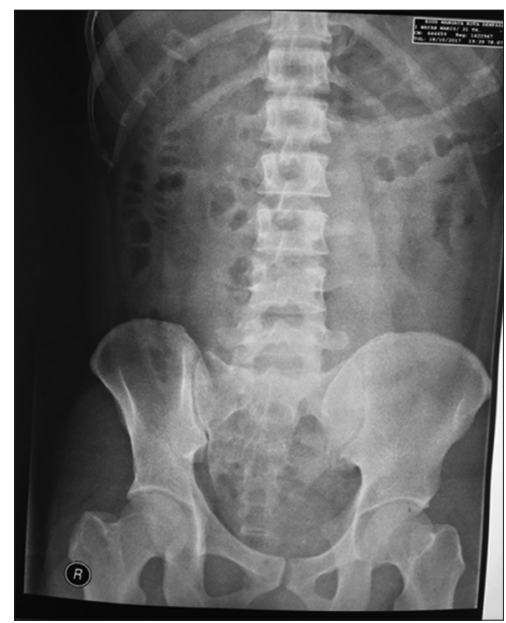

Fig. 2: Plain abdominal radiograph
HSP is classically characterized by tetrad of non-thrombocytopenic palpable purpura, arthritis or arthralgia, gastrointestinal, and renal involvement. Cutaneous manifestation is present in a majority of cases. Purpura in HSP is defined as palpable, non-blanching cutaneous hemorrhages $>1 \mathrm{~cm}$ in diameter. The erythematous rashes usually appear in dependent areas that are subject to pressure including lower extremities, belt line, and buttocks. The arthritis is non-migratory, transient, and leaves no deformity. Abdominal pain might mimic an acute abdomen due to its severity. Vomiting and gastrointestinal bleeding are common. Occult blood may be found in the fecal examination. Intussusception may also occur, but it is uncommon.

There are no specific serologic tests to diagnose HSP. Elevated IgA level is found in the majority of cases [6-8]. Although it is not specific, serum IgA measurement may help physicians to distinguish HSP/ IgA vasculitis from other forms of small vessel vasculitis such as antineutrophil cytoplasmic antibody-associated vasculitis, ChurgStrauss, and Wegener's granulomatosis [3,9]. Serum IgA measurement was not available in our hospital; hence, the diagnosis relies heavily on patient history and clinical manifestations.

Routine urinalysis is vital in patients with HSP. Microscopic hematuria is the most sensitive finding suggestive of IgA nephropathy in the presence of vasculitis. In addition to hematuria, proteinuria is not uncommon in HSP. Renal involvements are more frequent and severe in adults compared to those in children [5,7]. HSP has been documented to occur in pregnancy. The diagnosis in this special population is challenging because the systemic signs and symptoms are similar to commonly encountered pregnancy complications such as preeclampsia. History of HSP during childhood is a major risk factor for developing hypertension and proteinuria in pregnancy [10].

In 1990, ACR proposed the first criteria to diagnose HSP derived from both clinical and histopathology findings. A patient is said to have HSP if at least two of four findings are present (Table 1), with a sensitivity of $87.1 \%$ and specificity of $87.7 \%$ [4].

Using the 2010 EULAR/PRINTO/PRES criteria shown in Table 4, a patient fulfills the diagnosis of HSP when palpable purpura is present (mandatory), in addition to either abdominal pain, histopathology showing IgA deposition, the presence of arthralgia, or evidence of renal involvement [11].

However, the 2010 EULAR/PRINTO/PRES criteria for diagnosing HSP (Table 2) have its data sourced from pediatric patients, raising concerns it might not be suitable for use in the adult population. There was a study reviewing adult patients with positively diagnosed HSP from the 2012 International Chapel Hill Consensus Conference Nomenclature of Vasculitides to match the ACR and EULAR criteria. The result was the 2010 EULAR/PRINTO/PRES criteria had a $99.2 \%$ sensitivity and $86 \%$ specificity, compared to $86.8 \%$ sensitivity and $81 \%$ specificity using the 1990 ACR criteria. The better performance of 2010 EULAR/ PRINTO/PRES criteria is contributed by the addition of joint and renal involvements, which were not included in the old ACR criteria [12].

In our patient, a skin biopsy was not possible due to limitations in hospital pathologic facility, prohibiting the use of several diagnostic criteria where all require biopsy result to prove IgA deposition to distinguish the palpable purpura from other similar lesions such as drug-related hypersensitivity maculopapular eruption or ecchymosis [13-15]. This prompted the use of criteria from the 1990 American College of Rheumatology [4] criteria and the latest 2010 European League against Rheumatism/Paediatric Rheumatology International Trials Organisation/Paediatric Rheumatology European Society (EULAR/PRINTO/PRES) [11] to establish the working diagnosis of HSP in the absence of histopathology examination.

Early steroid initiation is beneficial to reduce gastrointestinal symptoms, prevent major complications, i.e., gastrointestinal bleeding or intussusception, and slow down the rate of renal progression. There 

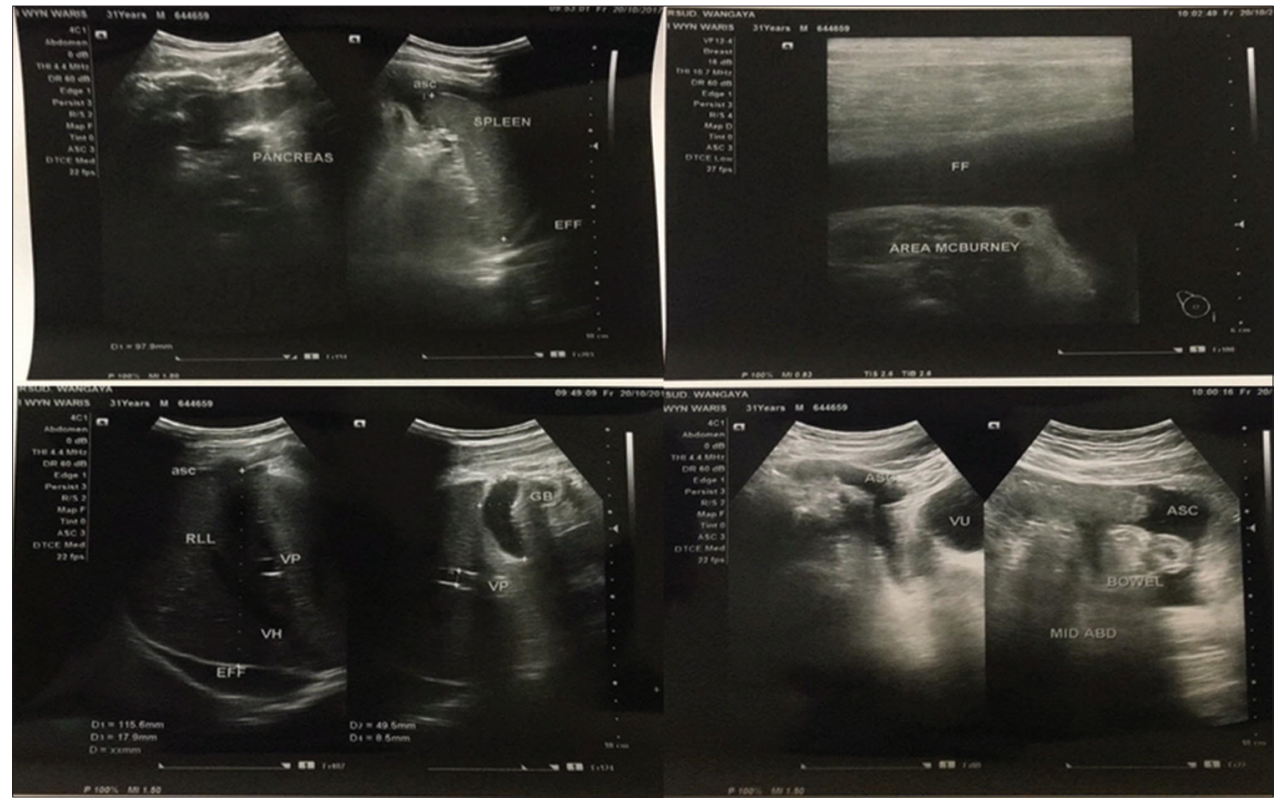

Fig. 3: Abdominal ultrasound, note the presence of free fluid in the abdominal cavity and pleural effusion

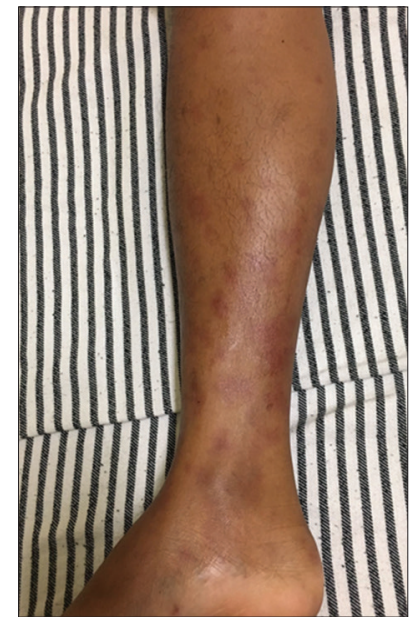

Fig. 4: Regressed palpable purpura

Table 1: ACR 1990 criteria for the classification of HenochSchönlein purpura [4]

\begin{tabular}{|c|c|}
\hline Criterion & Definition \\
\hline Palpable purpura & $\begin{array}{l}\text { Slightly raised "palpable" } \\
\text { hemorrhagic skin lesions, not } \\
\text { related to thrombocytopenia }\end{array}$ \\
\hline Age $\leq 20$ at disease onset & $\begin{array}{l}\text { Patients } 20 \text { years or younger at } \\
\text { onset of first symptoms }\end{array}$ \\
\hline Bowel angina & $\begin{array}{l}\text { Diffuse abdominal pain, worse after } \\
\text { meals, or the diagnosis of bowel } \\
\text { ischemia, usually including bloody } \\
\text { diarrhea }\end{array}$ \\
\hline Wall granulocytes on biopsy & $\begin{array}{l}\text { Histologic changes showing } \\
\text { granulocytes in the walls of } \\
\text { arterioles or venules }\end{array}$ \\
\hline
\end{tabular}

is no strict steroid dosing regimen in HSP treatment. This depends highly on the clinical manifestations of HSP and the severity of the disease. Steroid therapy is indicated in patients with severe rash, edema, severe abdominal pain, and renal involvement. Oral steroid is preferred when tolerated, methylprednisolone $1-2 \mathrm{mg} / \mathrm{kg} /$ day for up to 2 weeks then tapered down to $0.5 \mathrm{mg} / \mathrm{kg} /$ day over 1 week, and $0.5 \mathrm{mg} / \mathrm{kg}$ every other day for another 1 week. The same principle applies to intravenous steroid where the patient is unable to tolerate oral drug form [3].

Methylprednisolone pulse has been reported in successfully treating HSP with severe gastrointestinal signs and symptoms (severe abdominal tenderness, obstipation, vomiting, and absent bowel movement) resembling intestinal ischemia [16]. A prospective trial in adults supported this evidence, where methylprednisolone pulses followed by oral prednisolone provided excellent 10-year renal survival compared to a control group [17]. There is a reported case of HSP presenting with hemorrhagic ascites and extensive bowel thickening in computed tomography scan. Complete resolution was achieved with steroid therapy, without surgical intervention [18]. Low-dose intravenous methylprednisolone demonstrated satisfactory result in this case, leading to resolution of almost all symptoms, eliminating the necessity for surgery. Fig. 5 shows a proposed treatment algorithm for managing HSP patients according to each commonly found organ system involvements [5].

Nonsteroidal anti-inflammatory drugs are generally avoided to alleviate pain in patients with renal involvement and to prevent further exaggerate gastrointestinal symptoms. Paracetamol is safe to use even in renal impairment, providing mild analgesia to reduce the arthralgia. Few studies showed that colchicine has decent efficacy in terms of reducing inflammation in patients with cutaneous leukocytoclastic vasculitis, but evidence is limited, and relapse has been reported after discontinuation of colchicine. Leukotriene receptor antagonist has been used in children population, relieving symptoms, and inhibiting relapse. At present, there is not enough evidence supporting the benefit of using azathioprine in adult patients. Other immunosuppressive drugs including cyclosporin A, mycophenolate mofetil, and cyclophosphamide have been used in combination with steroid therapy for adult patients with nephrotic range proteinuria. Remission rates were better compared to those receiving steroid alone, although the statistical power was low in some studies [5]. We decided to manage the bowel angina and arthralgia with paracetamol as it was deemed to provide mild analgesia without compromising kidney function and avoiding the risk of further gastrointestinal side effects of nonsteroidal anti-inflammatory drugs. 


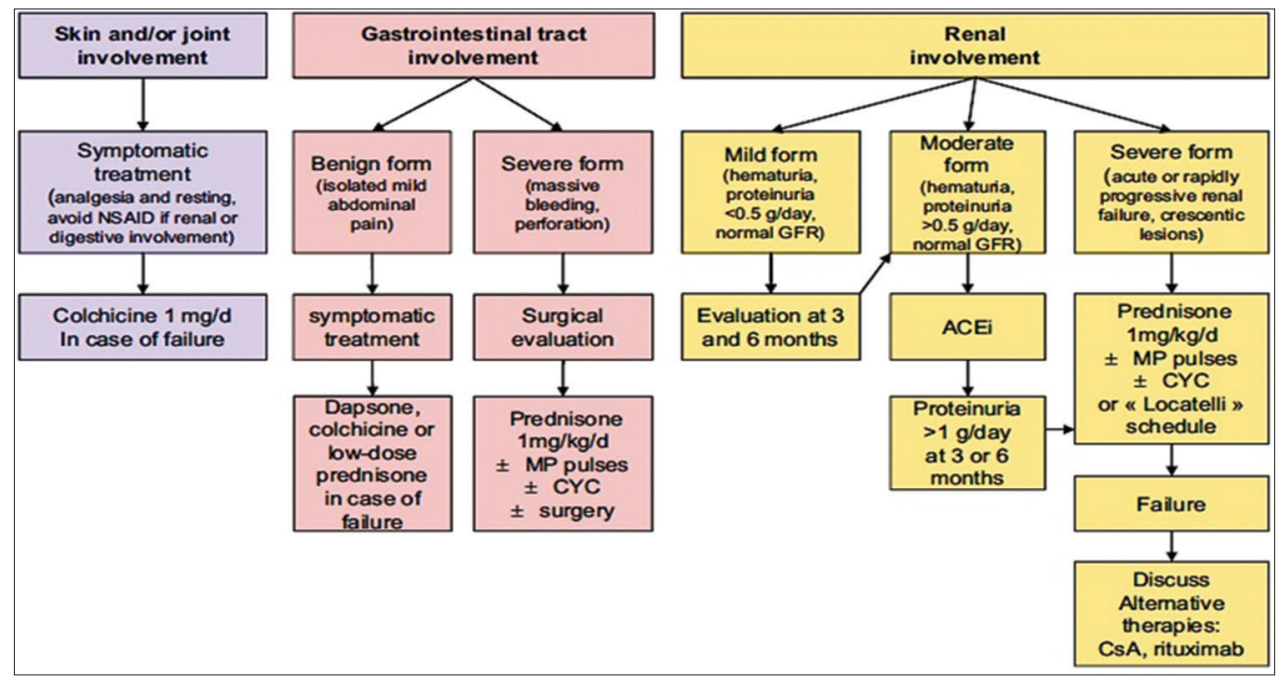

Fig. 5: Treatment algorithm for Henoch-Schönlein purpura [5]

Table 2: EULAR/PRINTO/PRES 2010 criteria for HenochSchönlein purpura [11]

\begin{tabular}{|c|c|}
\hline Criterion & Glossary \\
\hline Purpura (mandatory criterion) & $\begin{array}{l}\text { Purpura (commonly palpable and } \\
\text { in crops) or petechiae, with lower } \\
\text { limb predominance, not related to } \\
\text { thrombocytopenia }\end{array}$ \\
\hline Abdominal pain & $\begin{array}{l}\text { Diffuse abdominal colicky pain } \\
\text { with acute onset assessed by } \\
\text { history and physical examination. } \\
\text { May include intussusception and } \\
\text { gastrointestinal bleeding }\end{array}$ \\
\hline Histopathology & $\begin{array}{l}\text { Typically leukocytoclastic vasculitis } \\
\text { with predominant IgA deposit or } \\
\text { proliferative glomerulonephritis } \\
\text { with predominant IgA deposit }\end{array}$ \\
\hline Arthritis or arthralgias & $\begin{array}{l}\text { Arthritis of acute onset defined as } \\
\text { joint swelling or joint pain with } \\
\text { limitation on motion } \\
\text { Arthralgia of acute onset defined as } \\
\text { joint pain without joint swelling or } \\
\text { limitation on motion }\end{array}$ \\
\hline Renal involvement & $\begin{array}{l}\text { Proteinuria }>0.3 \mathrm{~g} / 24 \mathrm{~h} \text { or } \\
>30 \mathrm{mmol} / \mathrm{mg} \text { of urine albumin/ } \\
\text { creatinine ratio on a spot morning } \\
\text { sample } \\
\text { Hematuria or red blood cell } \\
\text { casts: }>5 \text { red blood cells/high } \\
\text { power field or red blood cells casts } \\
\text { in the urinary sediment or } \geq 2+\text { on } \\
\text { dipstick }\end{array}$ \\
\hline
\end{tabular}

IgA: Immunoglobulin A

Prognosis of HSP in adult is good, due to its self-limiting nature. Persistent renal damage is the most common complication in adultonset HSP. A long-term follow-up in one study reported persistent hematuria and renal failure needing hemodialysis in adults with HSP [19]. Recurrences within the first 6 months after onset are also more frequent in patients presenting with renal involvement. On the contrary, those without evidence of renal involvement at the onset of HSP may not develop permanent renal impairment. Blood pressure measurement and urinalysis should be performed in every follow-up visit.

Our patient had no episodes of macroscopic and microscopic hematuria throughout the hospitalization period. Serum urea and creatinine levels were within normal limits. In patients without any renal involvement such as in this case, a monthly urinalysis up to 6 months is recommended to facilitate early recognition of renal damage [7].

\section{CONCLUSION}

We report a case of a 31-year-old male presenting with palpable purpura and severe gastrointestinal symptoms diagnosed as HSP. Utilizing the 2010 EULAR/PRINTO/PRES criteria, the clinical diagnosis was established despite the lack of histopathology and serum IgA level examination. Despite the presence of free fluid within the abdominal cavity, complete resolution was achieved using intravenous steroid, without remaining abdominal symptoms, palpable purpura, arthralgia, or evidence of renal damage.

HSP is a small vessel systemic vasculitis rarely found in adults. It is a self-limiting disease and benign in nature. Nevertheless, severe cases of HSP in adults were reported from worldwide. Severe gastrointestinal manifestations mimicking surgical emergency may occur. Such event rarely requires urgent surgical intervention. Management for HSP varies from symptomatic treatments to immunosuppressive drugs. Steroid therapy was proven to be effective. Prognosis is generally good. Follow-up visits are needed, with blood pressure measurement and urinalysis every month up to 6 months to monitor recurrence and the possible evolution to renal impairment. This case serves as a reminder for physicians to increase awareness of HSP in adults. Refined documentations and/or studies on systemic vasculitis in Indonesia are highly necessary to provide better patient management.

\section{AUTHORS' CONTRIBUTION}

Dr. William Ray Cassidy as the main author is the attending Medical Officer wrote the manuscript. Dr. Dewi Catur Wulandari, the attending internal medicine specialist contributed significantly in providing guidance and reviewed the manuscript. Dr. Ketut Suryana as the Head of the Department of Internal Medicine, Allergy and Immunology Consultant supervised and reviewed the manuscript.

\section{CONFLICTS OF INTEREST}

The authors declare no conflicts of interest in preparing this article.

\section{REFERENCES}

1. Hung SP, Yang Yh, Lin YT, Wang LC, Lee JH, Chiang BL. Clinical manifestations and outcomes of henoch-schonlein purpura: Comparison between adults and children. Pediatr Neonatol 2009;50:162-8

2. Kang Y, Park JS, Ha YJ, Kang MI, Park HJ, Lee SW, et al. Differences 
in clinical manifestations and outcomes between adult and child patients with Henoch-Schönlein purpura. J Korean Med Sci 2014;29:198-203.

3. Sohagia AB, Gunturu SG, Tong TR, Hertan HI. Henoch-Schonlein purpura-a case report and review of the literature. Gastroenterol Res Pract 2010;2010:597648.

4. Mills JA, Michel BA, Bloch DA, Calabrese LH, Hunder GG, Arend WP, et al. The American college of rheumatology 1990 criteria for the classification of Henoch-Schonlein purpura. Arthritis Rheum 1990;33:1114-21.

5. Audemard-Verger A, Pillebout E, Guillevin L, Thervet E, Terrier B. IgA vasculitis Henoch-Shonlein purpura in adults: Diagnostic and therapeutic aspects. Autoimmun Rev 2015;14:579-85.

6. Jithpratuck W, Elshenawy Y, Saleh H, Youngberg G, Chi DS, Krishnaswamy G. The clinical implications of adult-onset HenochSchonelin purpura. Clin Mol Allergy 2011;9:9.

7. Reamy BV, Williams PM, Lindsay TJ. Henoch-Schonlein purpura. Am Fam Physician 2009;80:697-704.

8. Pillebout E, Thervet E, Hill G, Alberti C, Vanhille P, Nochy D. HenochSchonlein Purpura in adults: Outcome and prognostic factors. J Am Soc Nephrol 2002;13:1271-8.

9. Jennette JC, Falk RJ, Bacon PA, Basu N, Cid MC, Ferrario F, et al. 2012 Revised international Chapel Hill consensus conference nomenclature of vasculitides. Arthritis Rheum 2013;65:1-11.

10. Djakovic I, Butorac D, Vucicevic Z, Kosec V, Kuna AT, LugovićMihić L. Henoch-Schönlein purpura in the third trimester of pregnancy. Biochem Med 2018;28:010801.

11. Ozen S, Pistorio A, Iusan SM, Bakkaloglu A, Herlin T, Brik R, et al.
EULAR/PRINTO/PRES criteria for Henoch-Schonlein purpura, childhood polyarteritis nodosa, childhood Wegener granulomatosis and childhood Takayasu arteritis: Ankara 2008. Part II: Final classification criteria. Ann Rheum Dis. 2010;69:798-806

12. Hočevar A, Rotar Z, Jurčić V, Pižem J, Čučnik S, Vizjak A, et al. IgA vasculitis in adults: The performance of the EULAR/PRINTO/PRES classification criteria in adults. Arthritis Res Ther 2016;18:58.

13. Yang $\mathrm{YH}, \mathrm{Yu} \mathrm{H}$, Chiang B. The diagnosis and classification of HenochSchönlein purpura: An updated review. Autoimmun Rev 2014;13:355-8.

14. Joshisree KP, Rajesh G, Siddarama R: Corticosteroids induced ecchymosis. Int J Pharm Pharma Sci 2018;10:211-3.

15. Lakhsmi R, Liniya S, Vijayalakshmi S. Dapsone Induced hypersensitiity syndrome-a case report. Int J Pharm Pharm Sci 2015;7:585-7.

16. Sharma A, Wanchu A, Kalra N, Singh S, Bambery P. Successful treatment of severe gastrointestinal involvement in adult-onset HenochSchonlein purpura. Singapore Med J 2007, 48:1047-50.

17. Pozzi C, Andrulli S, Del Vecchio L, Melis P, Fogazzi GB, Altieri P, et al. Corticosteroid effectiveness in IgA nephropathy: Long-term results of a randomized, controlled trial. J Am Soc Nephrol 2004;15:157-63.

18. Lee BM, Jung HC, Bang SJ, Suh HS, Choi SW. A Case of HenochSchönlein Purpura complicated by hemorrhagic ascites. J Korean Rheum Assoc 2004;11:417-21.

19. García-Porrúa C, Calviño MC, Llorca J, Couselo JM, González-Gay MA, et al. Henoch-Schönlein purpura in children and adults: Clinical differences in a defined population. Semin Arthritis Rheum 2002;32:149-56. 